\title{
Fractional-order low-pass filter with electronic tunability of its order and pole frequency
}

\author{
Lukas Langhammer $^{*, * *}$, Jan Dvorak ${ }^{*}$, \\ Jan Jerabek ${ }^{*}$, Jaroslav Koton ${ }^{*}$, Roman Sotner ${ }^{* *}$
}

\begin{abstract}
This paper presents novel solution of a fractional-order low-pass filter (FLPF). The proposed filter operates in the current mode and it is designed using third-order inverse follow-the-leader feedback topology and operational transconductance amplifiers (OTAs), adjustable current amplifiers (ACAs), auxiliary multiple-output current follower (MO-CF) as simple active elements. The filter offers the beneficial ability of the electronic control of its order and also the pole frequency thanks to electronically controlled internal parameters of OTAs and ACAs. As an example, five particular values of fractional order of the FLPF were chosen and parameters of the filter were calculated. Similarly, also electronic control of the pole frequency of the filter was studied. The design correctness and proper function of the filter are supported by simulations with CMOS models and also by experimental laboratory measurements. Comparison of the simulation results of the proposed filter for two different approximations of the parameter $s^{\alpha}$ is also included.
\end{abstract}

K e y w or d s: adjustable current amplifier; current mode; electronically tunable; fractional-order; FLPF; low-pass filter; operational transconductance amplifier

\section{Introduction}

The issue of the fractional-order circuits is getting to the forefront of interest of many scientific teams [1-33]. Fractional order structures can be used for filtering the spectrum $[2,4-11,15,21]$, or the design of special oscillators $[12,25]$ or controllers $[17,22]$, for example. The fractional order circuits can find practical use in precision measurement, or modelling of various biological signals $[3,13,26]$. Another use may be in electrical engineering $[2-15,32]$, telecommunications [2] and also agriculture [16].

Order of a fractional-order filter is characterized by the slope of attenuation similarly as for conventional (integerorder) filters. The difference between a conventional filter and fractional-order filter is that the term determining the slope of attenuation of given transfer function contains additional parameter $\alpha$. Thus, the equation determining the slope of the attenuation of transfer function of a fractional-order filter is: $20(n+\alpha)(\mathrm{dB} /$ decade), where $n$ is an unsigned integer number [2-4], usually between 1 and 10 and $\alpha$ is defined as a real number in the range $0<\alpha<1$. There are two basic methods how to design fractional-order filter.

The first method is based on creation of a special fractional-order capacitor with impedance $Z_{C}=$ $1 / s^{\alpha} C[3,13,23,33]$ or inductor with impedance $Z_{L}=$ $s^{\alpha} L[29,31]$, which are then replacing respective passive components in the structure of a conventional fil- ter. These fractional-order passive elements are generally referred to as FOEs (fractional order elements) [14,24]. Significant attention is currently paid to creation of such elements. The most frequently used method of designing a fractional-order capacitor is using a RC ladder network $[13,18,19]$. This method is advantageous in terms of easy implementation. The disadvantage of this method is that the order of created filter has a fixed value and cannot be easily electronically controlled.

The other method is to create a special filter structure with specific values of passive components and transfers of active elements in order to approximate a fractionalorder function. To create a fractional-order function, an approximation by conventional filter of higher order is used $[2,4-7]$. Due to reasons of stability, it is necessary to design a filtering structure with the order of $(n+\alpha)>1$ $[4,20]$. The fundamental building element of this transfer function is Laplacian operator of fractional order $s^{\alpha}$ $[1,3,4]$. This operator is approximated by an integerorder function, usually a 2nd-order function is used as the simplest case $[3,4,7]$. Note that approximation of the operator $s^{\alpha}$ can also be performed using a higherorder function, which results in wider band of validity of approximation accuracy but also significant complexity of the circuit solution [4]. The transfer function that approximates the fractional-order filter can be implemented using several different topologies. The most widely used topologies are FLF (Follow the Leader Feedback) $[5,7,10,27,28]$, IFLF (inverse follow the leader

* Department of Telecommunications, Faculty of Electrical Engineering and Communication, Brno University of Technology, Technicka 3082/12, Brno, Czech Republic, langhammer@phd.feec.vutbr.cz (L.L.); dvorakjan@phd.feec.vutbr.cz (J.D.); jerabekj@feec.vutbr.cz (J.J.); koton@feec.vutbr.cz (J.K.), ** Department of Radio Electronics, Faculty of Electrical Engineering and Communication, Brno University of Technology, Technicka 3082/12, Brno, Czech Republic, sotner@feec.vutbr.cz (R.S.) 
Table 1. Comparison of the previously reported fractional-order filters

\begin{tabular}{|c|c|c|c|c|c|c|c|c|}
\hline Reference & $\begin{array}{l}\text { Active } \\
\text { elements } \\
\text { (number) }\end{array}$ & $\begin{array}{c}\text { Passive } \\
\text { parts } \\
\text { (number) }\end{array}$ & $\begin{array}{l}\text { Type } \\
\text { of } \\
\text { design }\end{array}$ & $\begin{array}{l}\text { Available } \\
\text { transfer } \\
\text { functions }\end{array}$ & $\begin{array}{c}\text { Electronic } \\
\text { control of the } \\
\text { pole frequency }\end{array}$ & $\begin{array}{l}\text { Electronic } \\
\text { control of } \\
\text { the order }\end{array}$ & $\begin{array}{l}\text { Simulated/ } \\
\text { Measured }\end{array}$ & $\begin{array}{c}\text { Operating } \\
\text { mode }\end{array}$ \\
\hline$[2]$ & $\mathrm{OA}(3)$ & $C(3), R(6)$ & FOE & LP & no & no & yes/no & $\overline{\mathrm{VM}}$ \\
\hline$[4]$ & $\mathrm{OA}(2)$ & $C(3), R(10)$ & higher-order & $\mathrm{LP}, \mathrm{BP}$ & no & no & yes/yes & $\mathrm{VM}$ \\
\hline$[8]$ & $\mathrm{OA}(3)$ & $C(2), R(6)$ & FOE & $\mathrm{LP}, \mathrm{BP}$ & no & no & yes/yes & VM \\
\hline$[9]$ & $\mathrm{OA}(3)$ & $C(2), R(6)$ & FOE & LP & no & no & yes/no & VM \\
\hline [11] & $\operatorname{DDCC}(5)$ & $C(3), R(7)$ & higher-order & LP & no & no & yes/yes & VM \\
\hline$[21]$ & $\operatorname{VCVS}(1)$ & $C(2), R(4)$ & FOE & LP & no & no & yes/yes & VM \\
\hline$[27]$ & $\begin{array}{c}\mathrm{DO}-\mathrm{CF}(1), \\
\mathrm{MO}-\mathrm{CF}(2), \\
\mathrm{ACA}(5)\end{array}$ & $C(3), R(3)$ & higher-order & LP & yes & yes & yes/yes & $\mathrm{CM}$ \\
\hline$[28]$ & $\begin{array}{l}\operatorname{OTA}(3), \\
\operatorname{DO}-\mathrm{CF}(1), \\
\operatorname{ACA}(2)\end{array}$ & $C(3)$ & higher-order & LP, HP & yes & yes & yes/yes & $\mathrm{CM}$ \\
\hline$[30]$ & CFOA(4) & $C(3), R(10)$ & higher-order & LP & no & no & no/yes & $\mathrm{VM}$ \\
\hline$[32]$ & $\begin{array}{c}\mathrm{DO}-\mathrm{CF}(2), \\
\mathrm{MO}-\mathrm{CF}(2), \\
\operatorname{ACA}(2)\end{array}$ & $C(3), R(3)$ & higher-order & LP & yes & yes & yes/no & $\mathrm{CM}$ \\
\hline$[33]$ & OTA (3) & $C(2)$ & FOE & $\mathrm{LP}, \mathrm{BP}$ & yes & no & yes/no & $\mathrm{CM}$ \\
\hline Fig. 7 & $\begin{array}{l}\operatorname{MOTA}(1), \\
\operatorname{OTA}(2), \\
\operatorname{ACA}(2), \\
\operatorname{MO}-\mathrm{CF}(1)\end{array}$ & $C(3)$ & Higher-order & LP & yes & yes & yes/yes & $\mathrm{CM}$ \\
\hline
\end{tabular}

List of previously unexplained abbreviations:

OA - Operational Amplifier, DDCC - Differential Difference Current Conveyor,

CFOA - Current Feedback Operational Amplifier, VCVS - Voltage Controlled Voltage Source,

OTA - Operational Transconductance Amplifier, MOTA - Multi-Output Transconductance Amplifier,

ACA - Adjustable Current Amplifier, DO-CF - Dual-Output Current Follower, MO-CF - Multi-Output Current Follower,

LP - Low Pass, BP - Band Pass, HP - High Pass, VM - Voltage Mode, CM - Current Mode.

feedback) [11], or SAB (single amplifier biquad) in combination with a 1st-order filter $[4,8]$. For the design of a fractional-order filter, a wide variety of commercially available types of active elements such as operational amplifiers (Op Amps) [2, 4, 8, 9, 12, 15, 21], differential difference current conveyors (DDCCs) [11], current feedback operational amplifiers (CFOAs) [30], second generation current conveyors (CCIIs) [34], transconductance amplifiers (OTAs) [35, 36], or current amplifiers (CAs) [37,38] can be used. Based on the type of elements used in the topology, some researchers try to control not only pole frequency or quality factor of the filter, but also the order of the filter itself $[10,27,28]$. However, this topic is still not fully researched and therefore, it requires our attention. Possibility to electronically control parameters of a fractional-order filter is a major advantage when comparing to filters using the FOEs that cannot be simply controlled electronically. However, the disadvantage of this approach can be the complexity and higher number of active elements in the filtering structure.

Most of the papers describe the design of a fractionalorder low-pass filter $[2,4-11,15,21,27,28]$, other also proposed transfer function of fractional-order high-pass filter $[6,7]$. Some papers present a proposal of a fractional- order band-pass filter $[4,8,15]$. The disadvantage is that a filter structure providing more transfer functions at once cannot be simply created since each filter function requires different values of parameters, or topology modifications $[4,6,7,8]$. As mentioned above, it is only possible to create filtering structures with the order of $1<n<2$ in frame of above mentioned topologies. In order to create a fractional-order function of a higher order $(n \geq 2)$, a cascade connection of an integer-order filter and $(1+\alpha)$ order filter has to be made $[2,4,7]$.

From the perspective of the operating mode and signal representation in case of fractional-order circuits, voltagemode is widely discussed $[2,4,8,9,11,15-17,21,24,26]$. However, due to growing need of circuits, which operate with low supply voltage and feature low power consumption it becomes more difficult to sustain sufficient signalto-noise ratio (SNR). Therefore, the current-mode solutions of fractional-order filters are also presented in the open literature [27, 28], as in particular cases, the current mode provides better SNR alongside with wider bandwidth, greater dynamic range and lower power consumption [39]. Table 1 contains a comparison of the fractionalorder low-pass filtering structures, which were mentioned in the text above. 


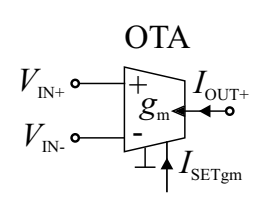

(a)

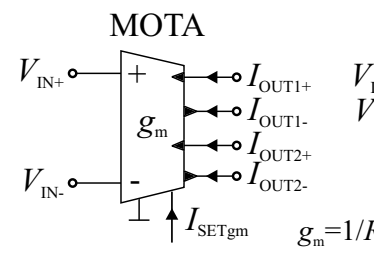

(b)

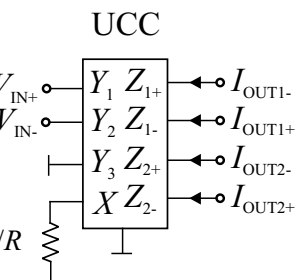

(c)

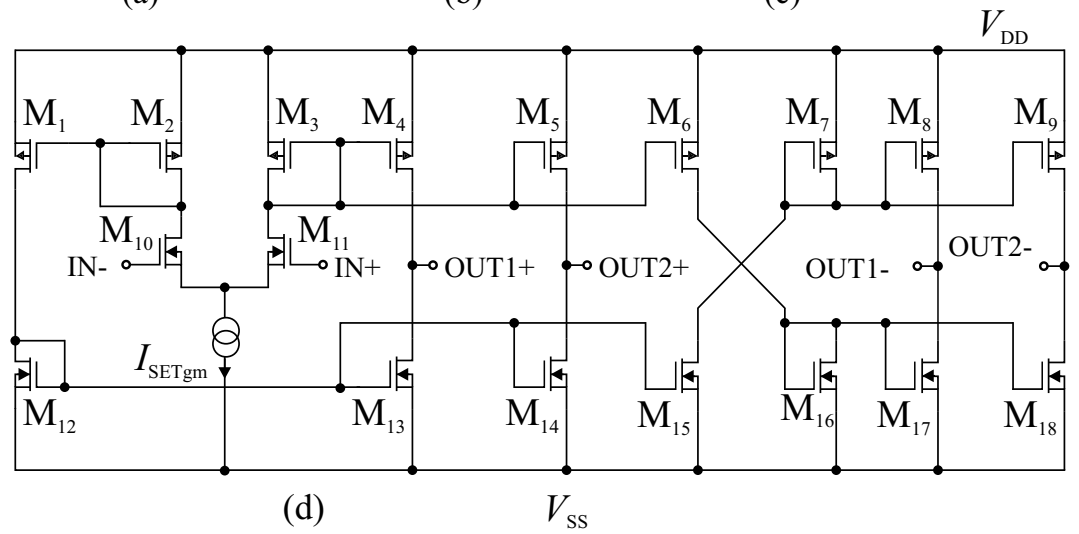

Fig. 1. (a) - Schematic symbol of operational transconductance amplifier (OTA), (b) - schematic symbol of multi-output transconductance amplifier (MOTA), (c) - possible implementation of MOTA by the universal current conveyor (UCC), (d) - CMOS implementation [35]

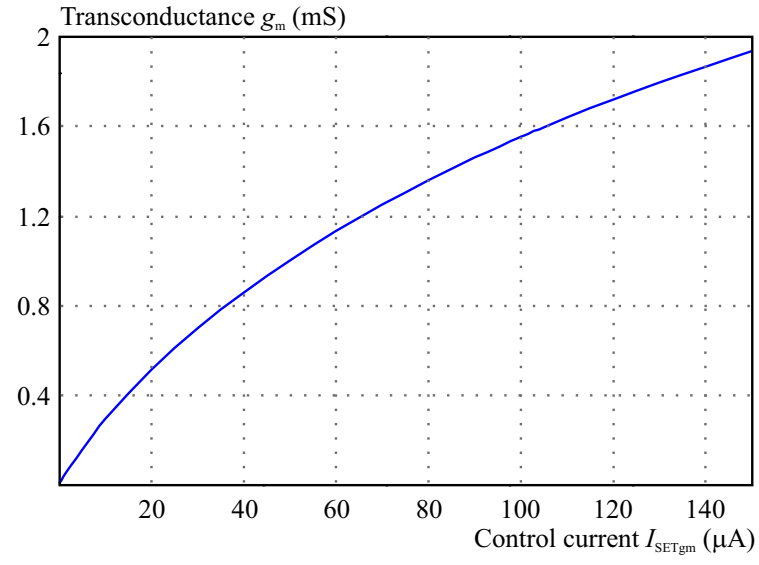

Fig. 2. Dependence of $g_{\mathrm{m}}$ on $I_{\mathrm{SET}_{\mathrm{gm}}}$ of the OTA (MOTA) element from Fig. 1(d)

Table 2. Dimensions of transistors of OTA CMOS model from Fig. 1(d)

\begin{tabular}{lc}
\hline Transistor & $\mathrm{W} / \mathrm{L}(\mu \mathrm{m})$ \\
\hline M1, M4-M9 & $10 / 0.36$ \\
M2, M3, M10-M18 & $20 / 0.36$ \\
\hline
\end{tabular}

The filter presented in this paper operates in current mode and provides a controllable fractional-order lowpass transfer function. IFLF topology was used to design the proposed filter. The filter consists of OTAs and ACAs. Thanks to the electronically controllable active elements which were used in the proposal, it is possible to electronically control the order and pole frequency of the filter which brings a big advantage in comparison to the most of the previously reported circuits $[2,4,8,9,11,21,30,33]$ which do not offer the electronic control of the filter parameters. Regarding the features of the proposed filter, its structure can be understood as simple, it can be eas- ily implemented and its properties can be verified not only by simulation but also by laboratory measurements with equivalent circuits of active elements as described in Section 2 .

\section{Description of Employed Active Elements}

Active elements that were used in the proposed filter are described in this section. The proposed filter employs three simple types of active elements.

The first used element is an operational transconductance amplifier (OTA) $[28,35,36]$, multi-output transconductance amplifier (MOTA) respectively. The schematic symbol of the OTA is shown in Fig. 1(a). The schematic symbol of the MOTA and possible behavioral implementation of the MOTA using a universal current conveyor (UCC) [34] can be seen in Figs. 1(b), (c), respectively. The universal current conveyor has been developed in CMOS $0.35 \mu \mathrm{m}$ technology at Brno University of Technology in cooperation with ON Semiconductor and is labeled as UCC-N1B0520. Each manufactured chip contains one UCC and one Second-Generation Current Conveyor with two outputs (CCII \pm ). A CMOS simulation model of the MOTA (OTA) used for PSpice simulations is illustrated in Fig. 1(d). This transistor-level simulation model was adopted from [35]. Note that the TSMC $0.18 \mu \mathrm{m}$ CMOS technology was used for implementation of the MOTA CMOS simulation model. The transconductance of this type of implementation of MOTA is controlled electronically by current $I_{\mathrm{SET}_{\mathrm{gm}}}$. Supply voltage is $\pm 1 \mathrm{~V}$.

OTA and MOTA consist of two input and one or more output terminals, respectively. Relations between 

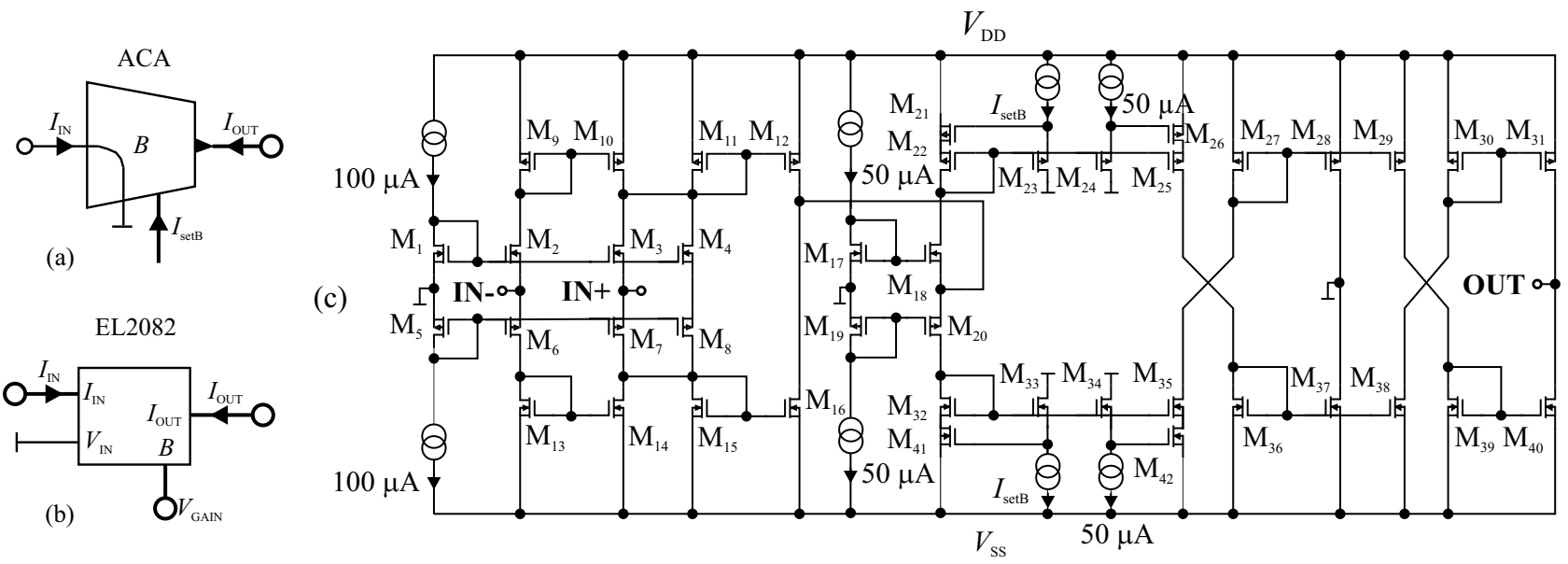

Fig. 3. Adjustable Current Amplifier (ACA): (a) - schematic symbol, (b) - possible implementation by EL2082 chip, (c) - used CMOS model [37]

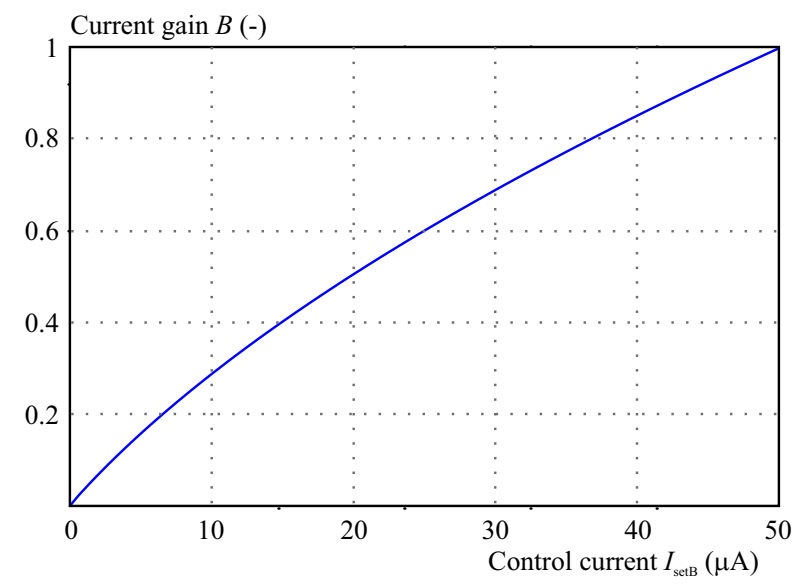

Fig. 4. Dependence of current gain on $I_{\mathrm{setB}}$ for ACA transistor level simulation model from Fig. 3(c)

Table 3. Dimensions of transistors in model from Fig. 3(c)

\begin{tabular}{lc}
\hline Transistor & $\mathrm{W} / \mathrm{L}(\mu \mathrm{m})$ \\
\hline M1-M4, M13-M16 & $10 / 0.54$ \\
M17, M18, M32-M35, M41, M42 & $30 / 0.54$ \\
M5-M12 & $37 / 0.54$ \\
M19-M26 & $111 / 0.54$ \\
M27-M31 & $37 / 0.9$ \\
M36-M40 & $10 / 0.9$ \\
\hline
\end{tabular}

input and output terminals are described as: $I_{\mathrm{OUT}+}=$ $-I_{\mathrm{OUT}-}=g_{\mathrm{m}}\left(V_{\mathrm{IN}+}-V_{\mathrm{IN}-}\right)[28]$.

Figure 2 shows the dependence of $g_{m}$ parameter of the used simulation model of the OTA (MOTA) element on control current $I_{\mathrm{SET}_{\mathrm{gm}}}$.

Dimensions of the transistors of the MOTA element from Fig. 1(d) are summarized in Table 2.

The second used active element is an adjustable current amplifier (ACA) $[27,28,37,38]$. The schematic symbol of this element is illustrated in Fig. 3(a). The ACA element have been implemented by behavioral model with EL2082 chips (Fig. 3(b)). Current gain of the EL2082 chip is controlled by external DC voltage [40]. Figure 3(c) shows used CMOS simulation model (implemented with $0.18 \mu \mathrm{m}$ CMOS technology) which was adopted from [37]. Supply voltage is $\pm 1 \mathrm{~V}$. Note that the current gain $(B)$ is controlled by current $I_{\mathrm{setB}}$. The behavioral model of the ACA consists of one input and output terminal. This active element can be described by the following relation: $I_{\mathrm{OUT}}=B I_{\mathrm{IN}}[28]$. Note that CMOS model of the ACA contains also inverting input terminal which is not connected in the case of the proposed filter. The dependence of current gain of the used transistor level simulation model of the ACA element on control current $I_{\text {setB }}$ is shown in Fig. 4.

Table 3 summarizes determined dimensions of the transistors of the ACA CMOS simulation model [37].

Table 4. Dimensions of transistors in model from Fig. 5(c)

\begin{tabular}{lc}
\hline Transistor & $\mathrm{W} / \mathrm{L}(\mu \mathrm{m})$ \\
\hline M1, M2 & $8 / 1$ \\
M14-M16 & $2 / 1$ \\
M10, M11, M17-M23 & $5 / 1$ \\
M3-M9, M12, M13 & $20 / 1$ \\
\hline
\end{tabular}

The auxiliary active element is a Multiple-Output Current Follower (MO-CF) $[27,36,37]$. Figure 5(a) shows its schematic symbol. Possible behavioral implementation of the MO-CF element using the UCC that is well-suited for measurement purposes is shown in Fig. 5(b). Used CMOS simulation model of the MO-CF (implemented with $0.18 \mu \mathrm{m}$ CMOS technology) can be seen in Fig. 5(c). Supply voltage is $\pm 1 \mathrm{~V}$. Transistor dimensions are summarized in Table 4 [36].

The MO-CF consists of one input and four output terminals. Relations between input and output terminals can be described by the following equations: $I_{\text {OUT1+ }}=$ $I_{\mathrm{OUT} 2+}=I_{\mathrm{IN}}, I_{\mathrm{OUT} 1-}=I_{\mathrm{OUT} 2-}=-I_{\mathrm{IN}}[36]$. 


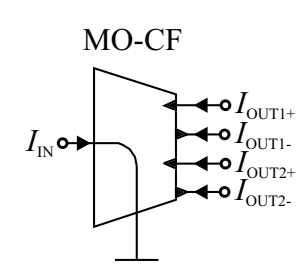

(a)

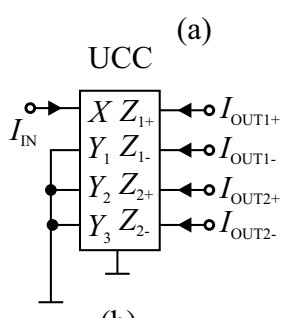

(b)

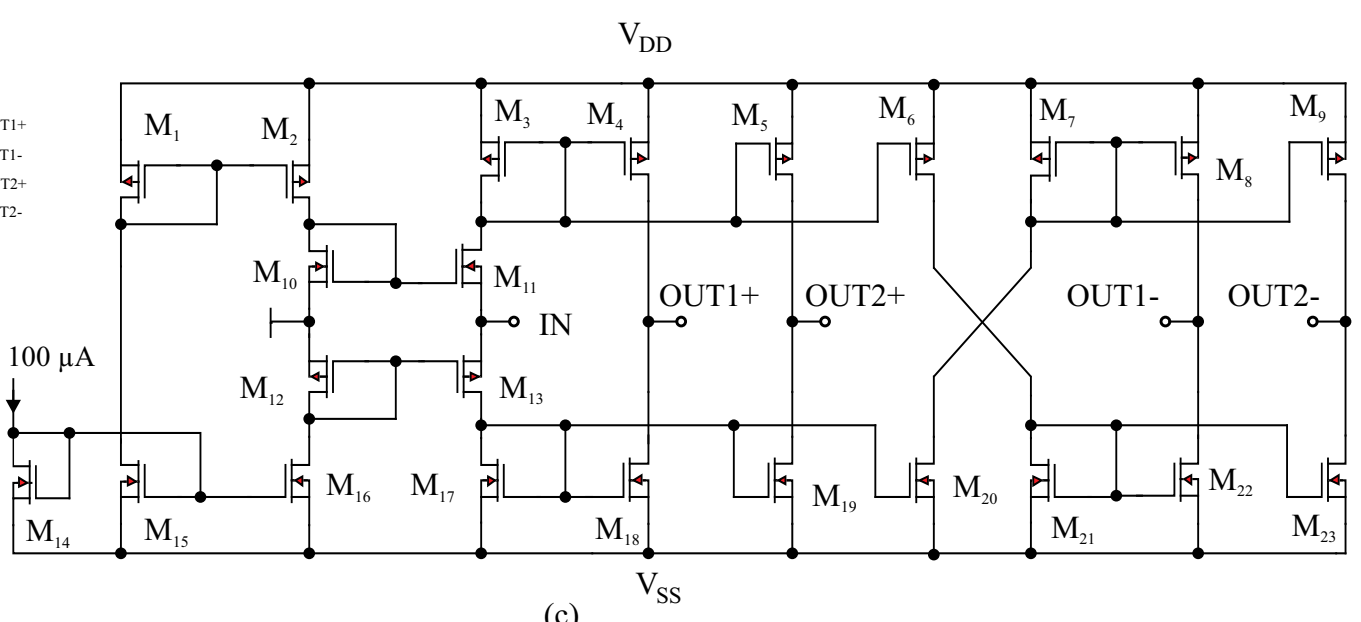

(c)

Fig. 5. Multiple-Output Current Follower (MO-CF): (a) - schematic symbol, (b) - implementation by the UCC, (c) - used CMOS model [36]

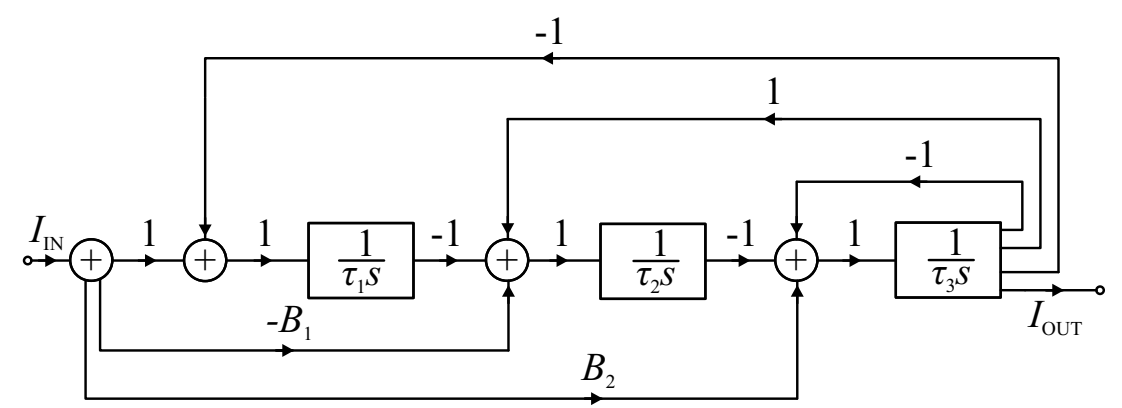

Fig. 6. Block diagram of the third-order Inverse Follow the Leader Feedback (IFLF) topology leading to $(1+\alpha)$-order low-pass filter

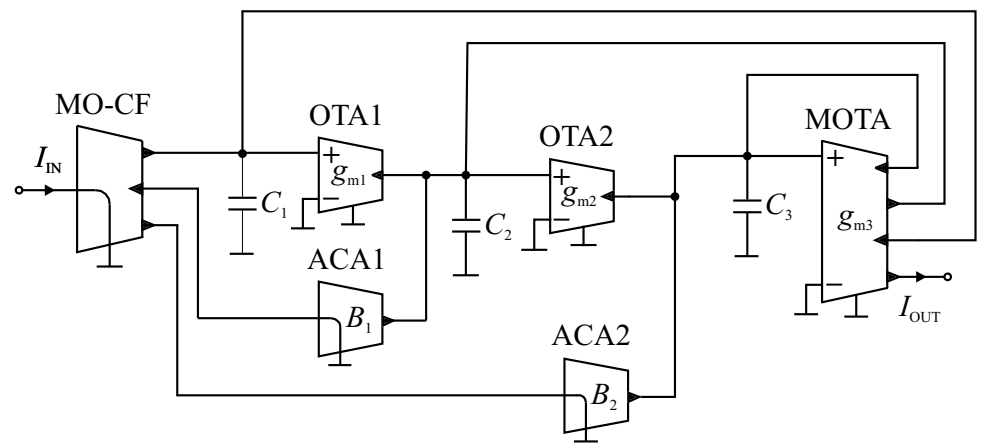

Fig. 7. Scheme of the $3^{\text {rd }}$-order CM filter approximating the $(1+\alpha)$-order low-pass filter

\section{Fractional-order Filter Proposal}

The transfer function of a $(1+\alpha)$-order fractional lowpass filter is given by [2]

$$
K_{1+\alpha}^{\mathrm{LP}}(s)=\frac{k_{1}}{s^{\alpha}\left(s+k_{2}\right)+k_{3}},
$$

where $k_{1}, k_{2}$ and $k_{3}$ are coefficients used to shape the pass-band region while keeping the desired fractionalorder slope of attenuation of the stop-band region. According to [6], in order to obtain fractional-order transfer functions with Butterworth characteristics, coefficients $k_{1}, k_{2}$ and $k_{3}$ from equation (1) have the following values [2]:

$$
\begin{aligned}
& k_{1}=1, \quad k_{2}=1.0683 \alpha^{2}+0.161 \alpha+0.3324, \\
& k_{3}=0.2937 \alpha+0.71216 .
\end{aligned}
$$

A second-order approximation of the term $s^{\alpha}$ discussed in introductory part is given by [4]

$$
s^{\alpha} \cong \frac{a_{0} s^{2}+a_{1} s+a_{2}}{a_{2} s^{2}+a_{1} s+a_{0}} .
$$

Using a second-order approximation of $s^{\alpha}$ introduced in [4], coefficients $a_{0}, a_{1}, a_{2}$ become

$$
a_{0}=2(1+\alpha), \quad a_{1}=5-\alpha^{2}, \quad a_{2}=2(1-\alpha) .
$$


Table 5. Summarization of parameters $C, g_{\mathrm{m}}$ and $B$ for selected values of the order when determining the coefficients $a$ according to (4)

\begin{tabular}{cccccc}
\hline Order of the filter $(1+\alpha)$ & 1.1 & 1.3 & 1.5 & 1.7 & 1.9 \\
\hline$g_{\mathrm{m} 1}(\mu \mathrm{S})\left(I_{\text {SETgm } 1}(\mu \mathrm{A})\right)$ & $160(4.90)$ & $170(5.38)$ & $182(5.67)$ & $198(6.20)$ & $212(6.80)$ \\
$g_{\mathrm{m} 2}(\mu \mathrm{S})\left(I_{\text {SETgm2 }}(\mu \mathrm{A})\right)$ & $358(13.00)$ & $342(11.68)$ & $345(11.96)$ & $363(13.29)$ & $378(13.65)$ \\
$g_{\mathrm{m} 3}(\mu \mathrm{S})\left(I_{\mathrm{SETgm} 3}(\mu \mathrm{A})\right)$ & $1130(62.00)$ & $906(45.32)$ & $817(40.39)$ & $810(40.30)$ & $903(45.45)$ \\
$B_{1}(-)\left(I_{\mathrm{setB} 1}(\mu \mathrm{A})\right)$ & $0.684(27.50)$ & $0.640(25.20)$ & $0.572(21.88)$ & $0.495(18.28)$ & $0.423(15.10)$ \\
$B_{2}(-)\left(I_{\mathrm{setB} 1}(\mu \mathrm{A})\right)$ & $0.253(8.15)$ & $0.193(5.98)$ & $0.131(3.82)$ & $0.072(1.94)$ & $0.021(0.51)$ \\
\hline
\end{tabular}

When using a second-order approximation presented in [6], the values of $a_{0}, a_{1}, a_{2}$ are

$$
\begin{aligned}
& a_{0}=\alpha^{2}+3 \alpha+2, \\
& a_{1}=8-2 \alpha^{2}, \\
& a_{2}=\alpha^{2}-3 \alpha+2 .
\end{aligned}
$$

By substitution of (3) into (1), the $(1+\alpha)$-order fractional low-pass transfer function turns into

$$
K_{1+\alpha}^{\mathrm{LP}}(s) \cong \frac{k_{1}}{a_{0}} \frac{a_{2} s^{2}+a_{1} s+a_{0}}{s^{3}+b_{2} s^{2}+b_{1} s+b_{0}},
$$

where $b_{0}=\left(a_{0} k_{3}+a_{2} k_{2}\right) / a_{0}, b_{1}=\left[a_{1}\left(k_{2}+k_{3}\right)+a_{2}\right] / a_{0}$ and $b_{2}=\left(a_{1}+a_{0} k_{2}+a_{2} k_{3}\right) / a_{0}$.

Transfer function (6) represents third-order transfer function that can be used for approximation of fractionalorder low-pass filter (FLPF). Structure in Fig. 6 illustrates a possible block diagram solution of given filter when inverse follow-the-leader feedback (IFLF) topology has been used.

The transfer function of the general structure represented by block diagram in Fig. 6 is

$$
K(s)=\frac{i(s)_{\mathrm{OUT}}}{i(s)_{\mathrm{IN}}}=\frac{\frac{B_{2}}{\tau_{1}} s^{2}+\frac{B_{1}}{\tau_{1} \tau_{2}} s+\frac{1}{\tau_{1} \tau_{2} \tau_{3}}}{s^{3}+\frac{1}{\tau_{1}} s^{2}+\frac{1}{\tau_{1} \tau_{2}} s+\frac{1}{\tau_{1} \tau_{2} \tau_{3}}} .
$$

The values of $B$ and $\tau$ parameters can be determined when comparing particular terms of (6) and (7).

The proposed filter based on topology shown in Fig. 7 has been designed based on the block diagram shown in Fig. 6. It consists of three transconductance amplifiers (two OTA and one MOTA elements), two ACAs, one auxiliary MO-CF and three grounded capacitors. It would be possible to reduce the number of active elements by two in case the parameters $B_{1}$ and $B_{2}$ were set solely passively (by current dividers), however that would narrow the range of adjustability of these parameters and also it would not be possible to control the order of the filter electronically as shown later.

The transfer function of the proposed filter can be described as

$$
\begin{aligned}
& K(s)=\frac{i(s)_{\mathrm{OUT}}}{i(s)_{\mathrm{IN}}}= \\
= & \frac{\frac{g_{\mathrm{m} 3} B_{2}}{C_{3}} s^{2}+\frac{g_{\mathrm{m} 2} g_{\mathrm{m} 3} B_{1}}{C_{2} C_{3}} s+\frac{g_{\mathrm{m} 1} g_{\mathrm{m} 2} g_{\mathrm{m} 3}}{C_{1} C_{2} C_{3}}}{s^{3}+\frac{g_{\mathrm{m} 3}}{C_{3}} s^{2}+\frac{g_{\mathrm{m} 2} g_{\mathrm{m} 3}}{C_{2} C_{3}} s+\frac{g_{\mathrm{m} 1} g_{\mathrm{m} 2} g_{\mathrm{m} 3}}{C_{1} C_{2} C_{3}}} .
\end{aligned}
$$

As mentioned earlier, most of the previously proposed fractional-order filters do not provide the feature of the electronic control (see Table 1). From the equation (8) should be evident that the proposed filter offers ability of the electronic control of its order by changing values of current transfers $B_{1}, B_{2}$ together with values of transconductances $g_{\mathrm{m} 1}, g_{\mathrm{m} 2}$ and $g_{\mathrm{m} 3}$. The filter also possesses ability to electronically control the pole frequency by adjusting values of transconductances $g_{\mathrm{m} 1}, g_{\mathrm{m} 2}$ and $g_{\mathrm{m} 3}$ when maintaining values of current gains $B_{1}, B_{2}$ unchanged.

\section{Experimental Verification}

To verify the functionality of the proposed filter, simulations and also experimental measurements were carried out. Simulation models (used for simulations) and practical implementation (used for lab measurements) of OTA (MOTA), MO-CF and ACA elements were presented in Section 2. Simulation results were obtained using PSpice. Experimental verification was performed by measurements of the implemented filter in the form of Printed Circuit Board (PCB), using simple V/I, I/V converters and a network analyser Agilent 4395A. The converters were implemented using circuits OPA860 [41] and OPA861 [42]. Obtained responses, which are included in this paper, are non-inverting transfer functions.

The initial values of specific filter parameters and passive parts for simulations and experimental measurements have been selected as follows: the starting pole frequency $f_{0}=100 \mathrm{kHz}$, initial value of order equal to 1.5 $(\alpha=0.5)$, capacitors $C_{1}=820 \mathrm{pF}, C_{2}=C_{3}=560 \mathrm{pF}$. The values of the capacitors are fixed for each of simulation and measurement setup. In case of experimental measurements, resistors representing value of $1 / g_{\mathrm{m}}$ (Fig. 1(c)) have been used and they were selected from E24 series (parallel combination of two E24 series resistors in some cases).

\subsection{Comparison of the approximations}

Analysis of the transfer function of the proposed filter when using two different approximations represented by coefficients $a_{0}, a_{1}, a_{2}$ from (4) and also from (5) has been made in order to determinate which coefficients will result in more accurate results (for this particular circuit structure). 


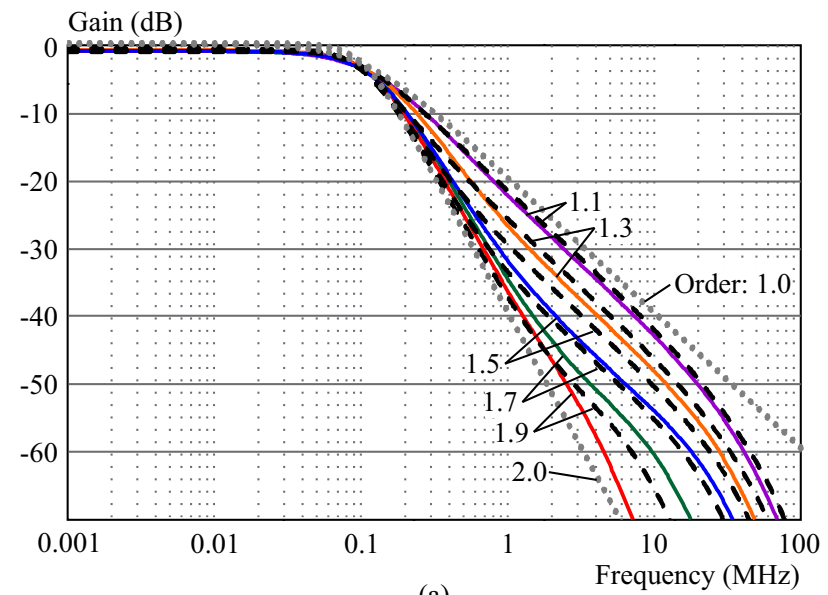

(a)

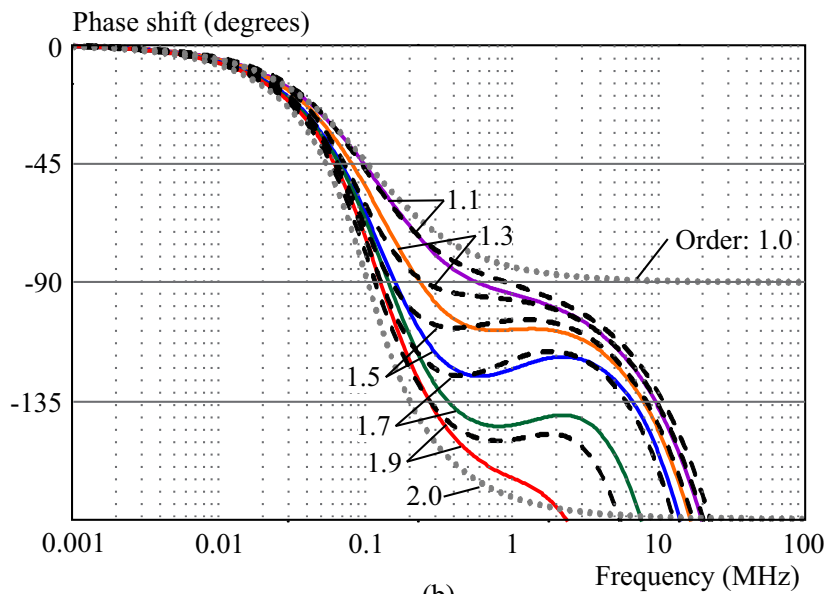

(b)

Fig. 8. Comparison of simulated transfer functions for five values of the order $(1+\alpha)$ when using two different approximations represented by different values of coefficients $a_{1}, a_{2}, a_{3}$. Dashed black lines represent results for coefficients from (4), colored solid lines are results for coefficients from (5) and grey dotted lines illustrate theoretical boundaries of investigated area: (a) - magnitude responses, (b) - phase responses

Table 6. Values of parameters $C, g_{\mathrm{m}}$ and $B$ for selected values of the order when using coefficients $a$ from $(5)$

\begin{tabular}{cccccc}
\hline Order of the filter $(1+\alpha)$ & 1.1 & 1.3 & 1.5 & 1.7 & 1.9 \\
\hline$g_{\mathrm{m} 1}(\mu \mathrm{S})\left(I_{\text {SETgm } 1}(\mu \mathrm{A})\right)$ & $113(3.26)$ & $133(3.95)$ & $145(4.43)$ & $175(5.39)$ & $207(6.74)$ \\
$g_{\mathrm{m} 2}(\mu \mathrm{S})\left(I_{\text {SETgm } 2}(\mu \mathrm{A})\right)$ & $361(12.77)$ & $375(13.29)$ & $374(13.27)$ & $409(15.38)$ & $408(15.36)$ \\
$g_{\mathrm{m} 3}(\mu \mathrm{S})\left(I_{\text {SETgm } 3}(\mu \mathrm{A})\right)$ & $1510(96.69)$ & $1170(66.32)$ & $928(46.10)$ & $914(45.45)$ & $959(48.68)$ \\
$B_{1}(-)\left(I_{\text {setB1 }}(\mu \mathrm{A})\right)$ & $0.760(31.46)$ & $0.700(28.28)$ & $0.610(23.72)$ & $0.515(19.18)$ & $0.428(15.27)$ \\
$B_{2}(-)\left(I_{\text {setB1 }}(\mu \mathrm{A})\right)$ & $0.170(5.15)$ & $0.117(3.37)$ & $0.070(1.88)$ & $0.033(0.81)$ & $0.008(0.17)$ \\
\hline
\end{tabular}

Table 7. Comparison of obtained slopes of attenuation and pole frequencies when using coefficients $a$ from (4) and (5)

\begin{tabular}{lccccc}
\hline Order of the filter $(1+\alpha)$ & 1.1 & 1.3 & 1.5 & 1.7 & 1.9 \\
\hline Theoretical slope of attenuation $(\mathrm{dB} / \mathrm{dec})$ & 22.0 & 26.0 & 30.0 & 34.0 & 38.0 \\
Slope of attenuation when using coefficients $a$ from $(4)(\mathrm{dB} / \mathrm{dec})$ & 20.0 & 22.6 & 27.2 & 31.8 & 37.2 \\
Slope of attenuation when using coefficients $a$ from $(5)(\mathrm{dB} / \mathrm{dec})$ & 21.1 & 25.4 & 29.8 & 34.1 & 37.3 \\
\hline Theoretical pole frequency for selected orders $(\mathrm{kHz})$ & 100 & 100 & 100 & 100 & 100 \\
Pole frequency when using coefficients $a$ from $(4)(\mathrm{kHz})$ & 107.5 & 101 & 99 & 103 & 101.8 \\
Pole frequency when using coefficients $a$ from $(5)(\mathrm{kHz})$ & 104.6 & 107 & 103 & 108 & 107.4 \\
\hline
\end{tabular}

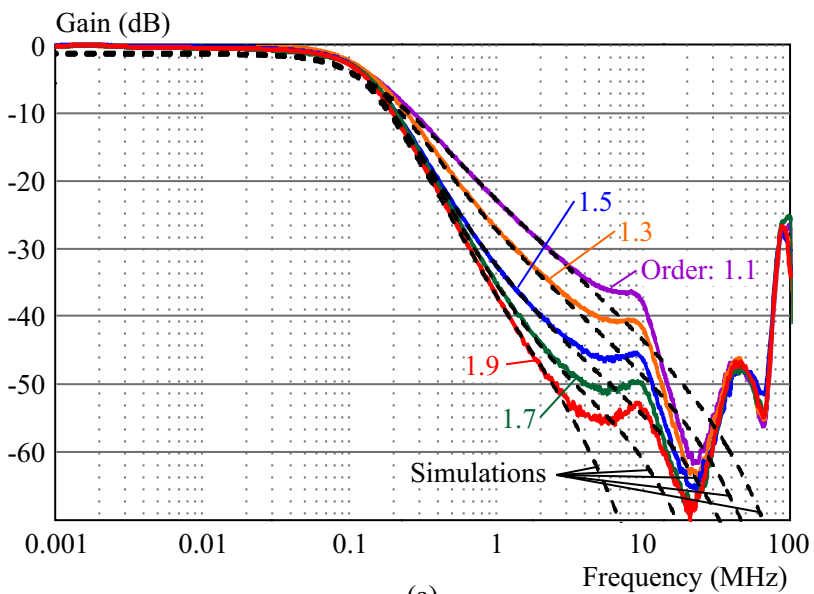

(a)

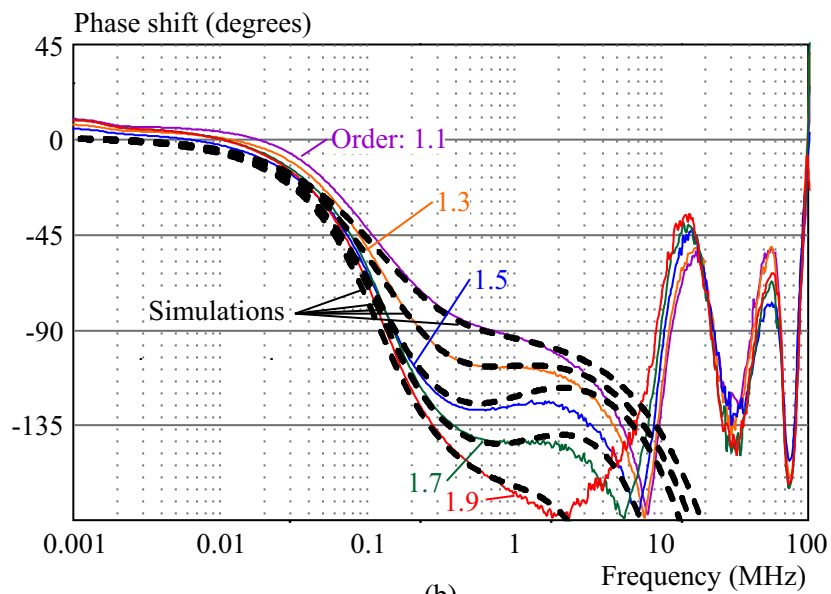

(b)

Fig. 9. Illustration of possibility to electronically control the order of the filter from Fig. 7 for particular orders 1.1, 1.3, 1.5, 1.7 and 1.9 when $f_{0}=100 \mathrm{kHz}$. Measurements (solid colored lines) vs simulations (dashed black lines) with CMOS models:(a) - magnitude responses, (b) - phase responses 
For above stated initial values of the pole frequency, order and capacitors, the transconductances and current gains in depending on used coefficients of approximation were calculated. Obtained values of transconductances and current gains are clearly summarized in Tab. 5 and Tab. 6. The tables also contain particular values of the control currents of the OTA and ACA CMOS models for calculated values of the transconductances and gains.

Table 5 summarizes calculated values of transconductances and current gains for five values of parameter $\alpha$ when using coefficients $a_{0}, a_{1}, a_{2}$ from (4).

The calculated values of transconductances and current gains for selected values of parameter $\alpha$ and coefficients $a_{0}, a_{1}, a_{2}$ from (5) are stated in Table 6 .

A comparison of the simulation results for selected values of order $(1+\alpha)(1.1,1.3,1.5,1.7,1.9)$ when analysing suitability of approximation represented by coefficients $a_{0}, a_{1}, a_{2}$ from (4) and (5) can be seen in Fig. 8. Transfer functions obtained when applying coefficients from (4) are illustrated as black dashed lines when colored solid lines express results obtained when using (5). The dotted lines represent the theoretical boundaries of investigated area.

Table 7 compares the obtained results regarding value of attenuation and pole frequency. It can be seen that the pole frequency of simulated transfer functions, which are using coefficients $a$ from (4), is closer to theoretical values. The values of the slope of attenuation are slightly different from the theoretical results. Nevertheless, when using coefficients $a$ from (5), the values of the slope of attenuation of the transfer functions are closer to the theoretical values as can be seen from Table 7. However, the values of the pole frequency are slightly less accurate in comparison with results for coefficients $a$ from (4).

From the viewpoint of accuracy of values of the slope of attenuation, coefficients $a_{1}, a_{2}, a_{3}$ from (5) have been used for further simulations and measurements.

\subsection{Comparison of simulation and measurement results for selected approximation}

This chapter provides comparison of PSpice simulations with CMOS models (Figs. 1, 3, 5) and measurement results for approximation represented by coefficients from (5). During the measurements, active elements (OTAs, MO-CF, ACAs) were behaviourally modelled as described in Section 2.

The ability to electronically control the order of the proposed filter is demonstrated by results shown in Fig. 9(a), (b). The ability to change the filter order has been tested for five values of the order $(1.1,1.3,1.5,1.7$, 1.9) when the pole frequency was $100 \mathrm{kHz}$.

Table 8 summarizes used values of $1 / g_{\mathrm{m}}$ selected from E24 series and current gains for chosen values of order of the filter $(1+\alpha)$.
Table 8. Summarization of used parameters $C, 1 / g_{\mathrm{m}}$ and $B$ for five values of order when $f_{0}=100 \mathrm{kHz}$

\begin{tabular}{lccccc}
\hline Order of the filter $(1+\alpha)$ & 1.1 & 1.3 & 1.5 & 1.7 & 1.9 \\
\hline $1 / g_{\mathrm{m} 1}(\mathrm{k} \Omega)$ & 8.889 & 7.500 & 6.800 & 5.739 & 4.764 \\
$1 / g_{\mathrm{m} 2}(\mathrm{k} \Omega)$ & 2.798 & 2.700 & 2.700 & 2.400 & 2.400 \\
$1 / g_{\mathrm{m} 3}(\mathrm{k} \Omega)$ & 0.667 & 0.847 & 1.100 & 1.100 & 1.048 \\
\hline$B_{1}(-)$ & 0.760 & 0.700 & 0.610 & 0.515 & 0.428 \\
$B_{2}(-)$ & 0.170 & 0.117 & 0.070 & 0.033 & 0.008 \\
\hline
\end{tabular}

From Fig. 9(a), it can be seen that the biggest differences between simulations (black dashed lines) and experimental measurements (colored solid lines) are at high frequencies, i.e. out of our scope of interest and out of range of validity of particular approximation. This is given mainly because of bandwidth limitations of the used active elements and also V/I, I/V converters and because of that the input/output impedances of used active elements have significant parasitic components. That applies also for all results presented below.

Values of the slope of attenuation for chosen values of order obtained from the simulations (black dashed lines) and experimental measurements (colored solid lines) are compared in Table 9. From the table it is obvious that all obtained simulated and measured values of the slope of attenuation are in good agreement with the theory.

Figure 9(b) illustrates the phase responses of the filter for selected orders when $f_{0}=100 \mathrm{kHz}$ as is also described above.

Table 10 contains comparison of obtained values of the phase shift. Values of the phase shift for adjusted pole frequency are mathematically described by $-45(n+$ $\alpha$ ) (degrees). From obtained simulation and measured results is obvious that values of phase shift, for values of the order from 1.1 to 1.5 , are relatively close to the theoretical results. The differences between theoretical, simulated and measured results, for orders 1.7 and 1.9, are given by very low current gain of the parameter $B_{2}$ as can be seen in the Table 8. It causes significant gain error in case of measurement, especially, and therefore also influences whole transfer characteristics.

The ability to electronically control the pole frequency of the proposed filter has been tested for five different frequencies. The pole frequencies chosen to illustrate this ability are 50,75, 100, 150 and $200 \mathrm{kHz}$ when the order of the filter is kept constant. As an example, we choose $\alpha=0.5$, ie order of the filter is 1.5 . Obtained simulation (black dashed lines) and measurement (colored solid lines) results are shown in Fig. 10(a), (b). Calculated values of the passive parts and $1 / g_{\mathrm{m}}$ for chosen values of $f_{0}$ are stated in Table 11. Note that the current gains were constant for all considered values of the pole frequency.

Table 12 compares the theoretical values of the pole frequency with pole frequencies obtained from simulations and experimental measurement. It can be seen that 


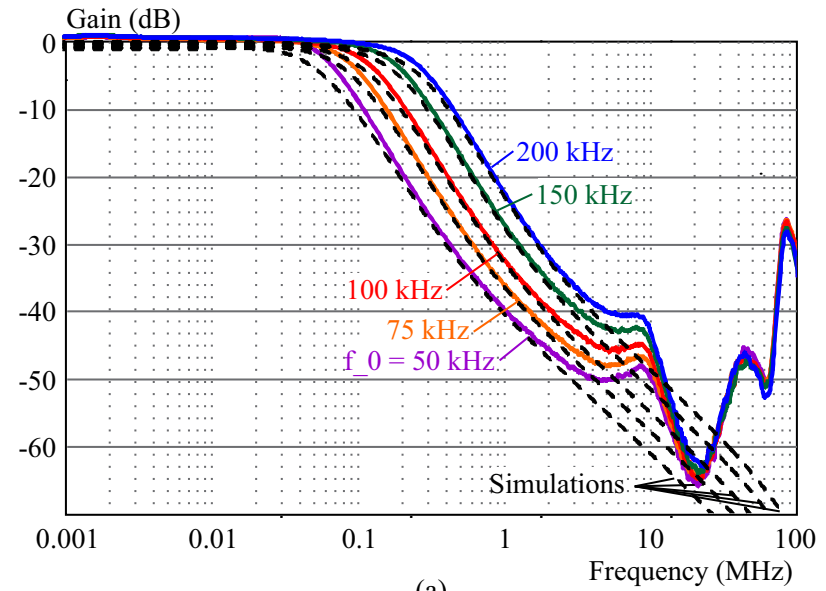

(a)

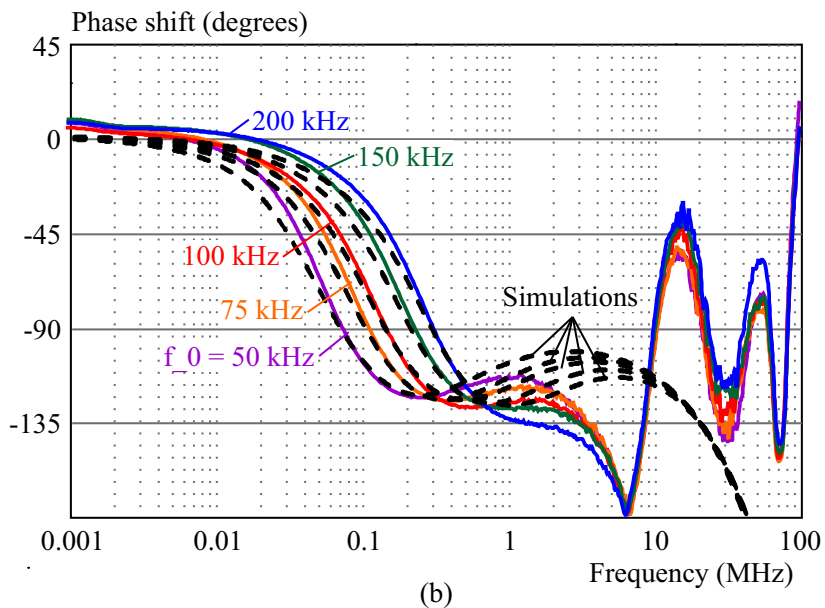

(b)

Fig. 10. Illustration of possibility to electronically control the pole frequency of the filter from Fig. 7 for five selected values of the pole frequency when order of the filter was 1.5. Measurement (solid colored lines) vs CMOS simulation (dashed black lines) results: (a) - Magnitude responses, (b) - Phase responses

Table 9. Summarization of theoretical, simulated and measured values of the slope of attenuation when changing the order of the filter

\begin{tabular}{lccccc}
\hline Order of the filter $(1+\alpha)$ & 1.1 & 1.3 & 1.5 & 1.7 & 1.9 \\
\hline Theoretical slope of attenuation $(\mathrm{dB} / \mathrm{dec})$ & 22.0 & 26.0 & 30.0 & 34.0 & 38.0 \\
Simulated slope of attenuation $(\mathrm{dB} / \mathrm{dec})$ & 21.0 & 25.4 & 29.8 & 34.1 & 36.2 \\
Measured slope of attenuation $(\mathrm{dB} / \mathrm{dec})$ & 21.9 & 26.0 & 30.4 & 34.7 & 37.5 \\
\hline
\end{tabular}

Table 10. Comparison of obtained values of the phase shift for five values of the order

\begin{tabular}{llcccc}
\hline Order of the filter $(1+\alpha)$ & 1.1 & 1.3 & 1.5 & 1.7 & 1.9 \\
\hline Theoretical values of phase shift (degrees) @ $100 \mathrm{kHz}$ & -49.5 & -58.5 & -67.5 & -76.5 & -85.5 \\
Simulated values of phase shift (degrees) @ $100 \mathrm{kHz}$ & -47.2 & -55.3 & -65.7 & -68.6 & -75.5 \\
Measured values of phase shift (degrees) @ $100 \mathrm{kHz}$ & -43.3 & -52.4 & -64.0 & -62.0 & -69.4 \\
\hline
\end{tabular}

Table 11. Used values of parameters $C, 1 / g_{\mathrm{m}}$ and $B$ for selected $f_{0}$ when order of the filter was 1.5

\begin{tabular}{lccccc}
\hline Theoretical pole frequency $(\mathrm{kHz})$ & 50 & 75 & 100 & 150 & 200 \\
\hline $1 / g_{\mathrm{m} 1}(\mathrm{k} \Omega)$ & 13.500 & 9.100 & 6.800 & 4.550 & 3.400 \\
$1 / g_{\mathrm{m} 2}(\mathrm{k} \Omega)$ & 5.500 & 3.600 & 2.700 & 1.800 & 1.300 \\
$1 / g_{\mathrm{m} 3}(\mathrm{k} \Omega)$ & 2.150 & 1.500 & 1.100 & 0.750 & 0.550 \\
\hline$B_{1}(-)$ & & & 0.610 & & \\
$B_{2}(-)$ & & & 0.070 \\
\end{tabular}

Table 12. Theoretical, simulated and measured values of the pole frequency when order of the filter was 1.5

\begin{tabular}{llllll}
\hline Theoretical pole frequency $(\mathrm{kHz})$ & 50.0 & 75.0 & 100.0 & 150.0 & 200.0 \\
\hline Simulated pole frequency $(\mathrm{kHz})$ & 52.0 & 76.2 & 104.6 & 154.2 & 207.7 \\
Measured pole frequency $(\mathrm{kHz})$ & 62.1 & 85.0 & 110.7 & 167.0 & 235.6 \\
\hline
\end{tabular}

Table 13. Comparison of obtained values of the phase shift for five values of the pole frequency when the order of the filter was 1.5

\begin{tabular}{llllll}
\hline Theoretical pole frequency (kHz) & 50.0 & 75.0 & 100.0 & 150.0 & 200.0 \\
\hline Theoretical values of phase shift (degrees) & & -67.5 \\
Simulated values of phase shift (degrees) & -69.2 & -67.6 & -65.7 & -67.1 & -63.5 \\
Measured values of phase shift (degrees) & -62.2 & -60.3 & -64.0 & -60.4 & -59.0 \\
\hline
\end{tabular}


the values of the pole frequency obtained from simulations and measurements are slightly higher than the theoretical values, yet the results prove the actual ability to electronically control the pole frequency when maintaining the desired order of the filter. It is caused by parasitics of used active elements and by inaccuracy of the values of passive components.

The phase responses of the fractional-order filter are presented in Fig. 10(b). The obtained values of the phase shift from simulations and measurements, for particular values of $f_{0}$, are compared in Table 13. Slight differences between simulated and measured results are seen from results in Table 13 and also from Figure 10(b).

\section{Conclusion}

The simulation and more importantly also experimental results confirm the design correctness and functionality of the proposed filter approximating $(1+\alpha)$-order low-pass filter. Chosen simulation and experimental results are illustrated in the paper and a comparison is made. The ability to electronically adjust the order and pole frequency of the proposed filter has been proved and discussed. Note that both this abilities are not available frequently in case of already published papers. The obtained values of order from simulations and experimental measurements are close to the theory and also mutually match very well. The obtained values of pole frequency are slightly higher than the theoretical values, nonetheless they also prove the ability to electronically control the pole frequency. Thanks to electronic control of both discussed parameters, particular shape and also pole frequency can be fine-tuned in final application of the filter.

\section{Acknowledgments}

Research described in this paper was financed by Czech Science Foundation under grant no. 16-06175S and the National Sustainability Program under grant LO1401. For the research, infrastructure of the SIX Center was used.

\section{REFERENCES}

[1] S. Das, Functional Fractional Calculus, second ed., Springer: Berlin, 2011.

[2] T. J. Freeborn, "Comparison of $(1+\alpha)$ Fractional-Order Transfer Functions to Approximate Lowpass Butterworth Magnitude Responses", Circuits, Systems, and Signal Processing, 2016, vol. 35, pp. 1983-2002.

[3] A. Elwakil, "Fractional-Order Circuits and Systems: An Emerging Interdisciplinary Research Area", IEEE Circuits and Systems Magazine, 2010, vol. 10, pp. 40-50.

[4] B. Maundy, A. S. Elwakil and T. J. Freeborn, "On the Practical Realization of Higher-Order Filters with Fractional Stepping", Signal Processing, 2011, vol. 91, pp. 484-491.

[5] G. Tsirimokou and C. Psychalinos, "Ultra-Low Voltage Fractional-Order Circuits using Current Mirrors", International Journal of Circuit Theory and Applications, 2016, vol. 44, pp. 109-126.
[6] T. J. Freeborn, B. Maundy and A. S. Elwakil, "Field Programmable Analogue Array Implementation of Fractional Step Filters", IET Circuits, Devices, 2010, vol. 4, pp. 514-524.

[7] G. Tsirimokou, C. Laoudias and C. Psychalinos, "0.5 V Fractional-Order Companding Filters", International Journal of Circuit Theory and Applications, 2015, vol. 43, pp. 1105-1126.

[8] T. J. Freeborn, B. Maundy and A. Elwakil, "Fractional-Step Tow-Thomas Biquad Filters", Nonlinear Theory and Its Applications, IEICE, 2012, vol. 3, pp. 357-374.

[9] T. Freeborn, B. Maundy and A. S. Elwakil, "Approximated Fractional Order Chebyshev Lowpass Filters", Mathematical Problems in Engineering, 2015, pp. 1-7.

[10] G. Tsirimokou, C. Psychalinos and A. S. Elwakil, "Digitally Programmed Fractional-Order Chebyshev Filters Realizations using Current-Mirrors", In 2015 IEEE International Symposium on Circuits and Systems, (ISCAS), IEEE, 2015, pp. 2337-2340.

[11] F. Khateb, D. Kubánek, G. Tsirimokou and C. Psychalinos, Fractional-order filters based on low-voltage DDCCs. Microelectronics Journal, 2016, 50, pp. 50-59.

[12] A. G. Radwan, A. S. Elwakil and A. M. Soliman, "Fractional-Order Sinusoidal Oscillators: Design Procedure and Practical Examples", IEEE Transactions on Circuits and Systems I: Regular Papers, 2008, vol. 55, pp. 2051-2063.

[13] T. J. Freeborn, "A Survey of Fractional-Order Circuit Models for Biology and Biomedicine", IEEE Journal on Emerging and Selected Topics in Circuits and Systems, 2013, vol. 3, pp. 416-424.

14] M. Sivarama Krishna, S. Das, K. Biswas and B. Goswami, "B. Fabrication of a Fractional Order Capacitor With Desired Specifications: A Study on Process Identification and Characterization", IEEE Transactions on Electron Devices, 2011, vol. 58, pp. $4067-4073$.

15] A. Soltan, A. G. Radvan and A. M. Soliman, "Fractional Order Filter with Two Fractional Elements of Dependant Orders", Microelectronics Journal, 2012, vol. 43, pp. 818-827.

16] T. Freeborn, M. Maundy and A. S. Elwakil, "Cole Impedance Extractions from the Step-Response of a Current Excited Fruit Sample", Computers and Electronics in Agriculture,, 2013, vol. 98, pp. 100-108.

[17] T. Haba, G. Loum, J. Zoueu and G. Ablart, "Use of a Component with Fractional Impedance in the Realization of an Analogical Regulator of Order 1/2", Journal of Applied Sciences, 2008, vol. 8, pp. 59-67.

[18] A. G. Radwan and K. N. Salama, "Fractional-Order RC and RL Circuits," Circuits, Systems, and Signal Processing, 2012, vol. 31, pp. 1901-1915.

19] P. Yifei, Y. Xiao, L. Ke, Z. Jiliu, Z. Ni, Z. Yi and P. Xiaoxian, "Structuring Analog Fractance Circuit for 1/2 Order Fractional Calculus", In Proc. 6th International Conference on ASIC, 2005, pp. $1136-1139$.

[20] M. D. Ortigueira, "An Introduction to the Fractional Continuous-Time Linear Systems: the 21st Century Systems", IEEE Circuits and Systems Magazine, 2008, vol. 8, pp. 19-26.

[21] A. S. Ali, A. G. Radwan and A. M. Soliman, "Fractional Order Butterworth Filter: Active and Passive Realizations", IEEE Journal on Emerging and Selected Topics in Circuits and Systems, 2013, vol. 3, pp. 346-354.

[22] I. Podlubny, I. Petras, B. M. Vinagre, P. O'Leary and L'. Dorcak, "Analogue Realizations of Fractional-Order Controllers", Nonlinear Dynamics, 2002, vol. 29, pp. 281-296.

[23] G. Carlson and C. Halijak, "Approximation of Fractional Capacitors $(1 / s)^{\wedge}(1 / n)$ by a Regular Newton Process", IEEE Transactions on Circuit Theory, 1964, vol. 11, pp. 210-213.

[24] G. Tsirimokou, C. Psychalinos, A. Allagui, and A. S. Elwakil, "Simple Non-Impedance-Based Measuring Technique for Supercapacitors", Electronics Letters,, 2015, vol. 51, pp. 1699-1701.

25] D. Kubanek, F. Khateb, G. Tsirimokou and C. Psychalinos, "Practical Design and Evaluation of Fractional-Order Oscillator 
Using Differential Voltage Current Conveyors", Circuits, Systems, and Signal Processing, 2016, vol. 35, pp. 2003-2016.

[26] T. Freeborn, B. Maundy and A. Elwakil, "Extracting the Parameters of the Double-Dispersion Cole Bioimpedance Model from Magnitude Response Measurements", Medical \& Biological Engineering \& Computing, 2014, vol. 52, pp. 749-758.

[27] J. Dvorak, L. Langhammer, J. Jerabek, J. Koton, R. Sotner and J. Polak, "Electronically Tunable Fractional-Order Low-Pass Filter with Current Followers", Journal of Circuits, Systems, and Computers, 2018, vol. 27, in press.

[28] J. Jerabek, R. Sotner, J. Dvorak, J. Polak, D. Kubanek, J. Koton and N. Herencsar, "Reconfigurable Fractional-Order Filter with Electronically Controllable Slope of Attenuation, Pole Frequency and Type of Approximation", Journal of Circuits, Systems, and Computers, 2017, vol 26, pp. 1-21.

[29] M. C. Tripathy, D. Mondal, K. Biswas and S. Sen, "Experimental Studies on Realization of Fractional Inductors and Fractional-Order Bandpass Filters", International Journal of Circuit Theory and Applications, 2015, vol.43, pp. 1183-1196.

[30] G. Tsirimokou, S. Koumousi and C. Psychalinos, "Design of Fractional-Order Filters Using Current Feedback Operational Amplifiers", In Proc. 3rd Pan-Hellenic conference on electronics and telecommunications (PACET 2015), 2015.

[31] R. Sotner, J. Jerabek, J. Petrzela and T. Dostal, "Simple Approach for Synthesis of Fractional-Order Grounded Immittances Based on OTAs", In Proc. 39th international conference on telecommunications and signal processing (TSP 2016), 2016, pp. $563-568$.

[32] L. Langhammer, R. Sotner, J. Dvorak, O. Domansky, J. Jerabek and J. Uher, "A $(1+\alpha)$ Low-Pass Fractional-Order Frequency Filter with Adjustable Parameters", In Proc. 40th international conference on telecommunications and signal processing (TSP 2017), 2017, pp. 724-729.

[33] R. Verma, N. Pandey and R. Pandey, "Electronically Tunable Fractional Order Filter", Arabian Journal for Science and Engineering, 2017, vol. 42, pp. 3409-3422.

[34] J. Jerabek and K. Vrba, "SIMO Type Low-Input and High-Output Impedance Current-Mode Universal Filter Employing Three Universal Current Conveyors", International Journal of Electronics and Communications (AEU), 2010, vol. 64, pp. 588-593.

[35] R. Sotner, N. Herencsar, J. Jerabek, R. Prokop, A. Kartci, T. Dostaland K. Vrba, "Z-Copy Controlled-Gain Voltage Differencing Current Conveyor: Advanced Possibilities in Direct Electronic Control of First-Order Filter", Elektronika ir elektrotechnika, 2014, vol. 20, pp. 77-83.

[36] J. Jerabek, R. Sotner and K. Vrba, "Electronically Adjustable Triple-Input Single-Output Filter with Voltage Differencing Transconductance Amplifier", Revue Roumaine des Sciences Techniques - Serie Électrotechnique et Énergétique, 2015, vol. 59, pp. $163-172$.

[37] J. Jerabek, R. Sotner and K. Vrba, "General Current-Mode Filtering Structure with Controllable Current Active Elements", In Proc. 36th international conference on telecommunications and signal processing (TSP 2013), 2013, pp. 402-406.

[38] J. Polak, J. Jerabek, L. Langhammer, R. Sotner, J. Dvorak and D. Panek, "Digitally Controllable Current Amplifier and Current Conveyors in Practical Application of Controllable Frequency Filter", Journal of Electrical Engineering, 2016, vol. 67, pp. 261-266.

[39] C. Toumazou, F. J. Lidgey and D. G. Haigh, "Analog IC Design: the Current-Mode Approach", Institution of Electrical Engineers: London, 1996.

[40] EL2082 (Elantec) Current-mode multiplier (datasheet), Intersil, 1996.
41] OPA860 Wide Bandwidth Operational Transconductance Amplifier (datasheet), Texas Instruments, 2008.

42] OPA861 Wide Bandwidth Operational Transconductance Amplifier (datasheet), Texas Instruments; 2013.

Received 28 September 2017

Lukas Langhammer received the $\mathrm{MSc}$ and $\mathrm{PhD}$ degree in the field of electrical engineering and telecommunication from the Faculty of Electrical Engineering and Communications, Brno University of Technology (BUT), Brno, Czech Republic, in 2012 and 2016, respectively. He is currently with a department of Radio Electronics at the same faculty. His current work is focused on fully-differential, fractional-order and electronically configurable frequency filters.

Jan Dvořák was born in Boskovice, Czech Republic, in 1990. He received the MSc degree from the Brno University of Technology, Czech Republic, in 2015. He is currently with the department of Telecommunications, Faculty of Electrical Engineering and Communication, Brno University of Technology, Czech Republic. His interests are in area of analogue circuits, their design and verification of their features by simulations and experimental measurements. His work is focused on fractional-order and integer-order frequency filters in the current mode, electronically tunable and reconfigurable frequency filters and fractional-order elements.

Jan Jeřábek was born in Bruntal, Czech Republic, in 1982. He received the $\mathrm{PhD}$ degree in electrical engineering from the Brno University of Technology, Brno, Czech Republic, in 2011.He is currently an Associate Professor with the Faculty of Electrical Engineering and Communication, Department of Telecommunications, Brno University of Technology. He researches mainly in area of analogue circuits, methods of their design, analysis and verification of their features by computer simulations and also by laboratory measurements. $\mathrm{He}$ is interested in both integer-order and fractional-order circuits, especially frequency filters and oscillators.

Jaroslav Koton was born in Hustopeče, Czech Republic, in 1981. He received the MSc and PhD degrees in Electrical Engineering from Brno University of Technology in 2005 and 2009, respectively. At Brno University of Technology, he is currently an Associate Professor at the Department of Telecommunications. Next to his research activities, he serves as vicedean at the Faculty of Electrical Engineering and Communication. As a senior researcher he also works for the SIX Research Centre and is the vice-head of the Converged Systems group. His research and development activities are focused on integer and fractional-order liner- and non-linear circuit design methods with current or voltage conveyors, and current active elements.

Roman Šotner was born in Znojmo, Czech Republic, in 1983. He received the MSc and $\mathrm{PhD}$ degrees from the Brno University of Technology, Czech Republic, in 2008 and 2012, respectively. Currently, he is an Assistant Professor at the Department of Radio Electronics, Faculty of Electrical Engineering and Communication, Brno University of Technology, Brno, Czech Republic. His interests are analog circuits (active filters, oscillators, audio, etc), circuits in the current mode, circuits with direct electronic controlling possibilities especially and computer simulation. 